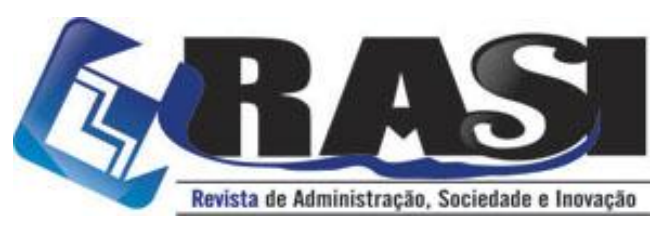

http://www.rasi.uff.br

RASI, Volta Redonda/RJ, v. 4, n. 2, pp. 160-182, jul./dez. 2018

\title{
Perfil Orçamentário de Pequenos Municípios: O Caso do Município de Ladainha - MG
}

\author{
Fernanda Aparecida Guedes Honorato da Silva (UFVJM) - faghs.nanda@gmail.com \\ Mirelle Cristina de Abreu Quintela (UFVJM) - mirelleab@gmail.com \\ Naldeir dos Santos Vieira (UFVJM) - naldeir.vieira@ufvjm.edu.br
}

\begin{abstract}
RESUMO: Elevados os municípios à categoria de entes federados, houve aumento das responsabilidades destes no atendimento às demandas da população e na participação da arrecadação tributária nacional. Contudo, a arrecadação própria não supre as despesas municipais. É cada vez maior a dependência financeira em relação aos entes superiores. Neste contexto federativo, conhecer a disponibilidade de recursos financeiros e o perfil das despesas municipais é fundamental para a identificação de problemas e levantamento de soluções que integrem a atuação dos poderes municipais, estaduais e federal e, igualmente importante, a sociedade. É uma forma de oportunizar a conscientização fiscal, subsidiar o controle social e promover o exercício da cidadania, face aos instrumentos de planejamento e gestão municipal. Neste sentido, propõe-se, neste trabalho, identificar o perfil orçamentário do município de Ladainha/MG no período de 2000 a 2016. Para isto, analisaram-se dados do período citado, identificando o comportamento temporal das receitas (captação e origem) e das despesas (natureza e finalidade). Depreendeu-se que o município de Ladainha, por ser de pequeno porte e predominantemente rural, tem arrecadação própria insuficiente e depende das Transferências Intergovernamentais para financiar seus gastos, que se concentram majoritariamente nas áreas de Educação e Cultura e Saúde e Saneamento.
\end{abstract}

PALAVRAS-CHAVE: Perfil Orçamentário, Orçamento Municipal, Receitas Municipais, Despesas Municipais.

Budget Profile of Small Municipalities: the case of the municipality of Ladainha - MG

ABSTRACT: Higher municipalities to the category of federated entities, there was an increase in their responsibilities in meeting the demands of the population and in the participation of the national tax collection. However, own collection does not cover municipal expenses. Financial dependence on higher entities is increasing. In this federative context, knowing the availability of financial resources and the profile of municipal expenditures is fundamental for the identification of problems and solutions that integrate the performance of municipal, state and federal powers and, equally importantly, society. It is a way of promoting fiscal awareness, subsidizing social control and promoting the exercise of citizenship, in the face of planning and municipal management instruments. In this sense, it is proposed to identify the budget profile of the municipality of Ladainha / MG in the period from 2000 to 2016. For this, data from the mentioned period were analyzed, identifying the time behavior of revenues (funding and origin) and expenditures (nature and purpose). It was found that the municipality of Ladainha, because it is small and predominantly rural, has insufficient own collection and depends on the Intergovernmental Transfers to finance its expenses, which are concentrated mainly in the areas of Education and Culture and Health and Sanitation.

KEYWORDS: Budgetary Profile, Municipal Budget, Municipal Revenues, Municipal Expenditures.

\begin{tabular}{c} 
R. Universidade \\
Fesembargador Ellis Hermydio Figueira, 783, Bloco A, sl. 218, Aterrado. \\
$27213-415$ - Volta Redonda, RJ - Brasil \\
www.uff.br \\
\hline $\begin{array}{c}\text { Copyright (C) 2018 RASI. Todos os direitos, até mesmo de tradução, são reservados. É } \\
\text { permitido citar parte de artigos sem autorização prévia, desde que seja identificada a fonte }\end{array}$ \\
\hline
\end{tabular}




\section{Perfil Orçamentário de Pequenos Municípios: O Caso do Município de Ladainha - MG}

\section{Introdução}

Com a Constituição de 1988, o Brasil reforçou a estrutura federalista prevendo uma maior descentralização dos níveis de governo do Estado entre União, estados-membro e municípios. No entanto, essa descentralização não refletiu no equilíbrio entre a geração de receitas e responsabilidades, existindo uma concentração de recursos públicos arrecadados na União e sobrecarga de atribuições aos municípios. Com a transferência de responsabilidades para os municípios, há um maior deslocamento de recursos do centro (nível federal) para o periférico (municípios). Esse movimento aumentou a dependência das gestões locais em relação aos entes federativos mais poderosos, principalmente pela grande desigualdade existente entre as unidades da Federação (Arretche, 1996; Pires, 2013).

Mesmo com essa maior participação na arrecadação tributária do país, o que se observa é cada vez mais uma dependência financeira dos municípios em relação aos entes superiores, por não conseguirem, apenas com a arrecadação própria, suprir as despesas municipais, o que é corroborado pelos resultados dos trabalhos dos autores Brito e Dias (2012), Santos e Santos (2014) e Leroy e Bontempo (2017).

Neste contexto, dos gestores públicos municipais são exigidas atuações mais direcionadas às necessidades da população, bem como ações para o desenvolvimento regional, cabendo a estes a escolha de como os recursos arrecadados, que são escassos, serão investidos nos gastos municipais, respeitando os limites estabelecidos na Constituição de 1988 e na Lei de Responsabilidade Fiscal (LRF) e atentando aos dispositivos que regulam as atividades orçamentárias como Plano Plurianual (PPA), Lei de Diretrizes Orçamentárias (LDO) e Lei Orçamentária Anual (LOA).

Os desafios da gestão orçamentária municipal perpassam o entendimento da organização orçamentária municipal. Desta forma, conhecer o perfil orçamentário dos pequenos municípios, identificando as principais fontes de captação de recursos disponíveis e suas principais despesas é fundamental para almejar o equilíbrio das contas públicas. $\mathrm{O}$ conhecimento do perfil orçamentário do município pode tornar mais efetivo o processo de identificação de problemas locais e o levantamento de soluções que integrem a atuação dos poderes municipal, estadual e federal. Ademais, dará subsídios a uma conscientização fiscal e ao controle social, de forma a promover o exercício da cidadania por meio da participação cidadã no planejamento e controle para a gestão municipal.

Uma vez que a maioria dos municípios brasileiros é de pequeno porte, característica evidenciada no estado de Minas Gerais que possui 853 municípios, sendo 80,5\% com população inferior a 20.000 habitantes, estudar as origens das receitas e em quais áreas prevalece a sua aplicação é essencial para entender e melhorar a gestão orçamentária municipal. Tomou-se como objeto de estudo o município de Ladainha, com uma população estimada de 18.066 habitantes, localizado no Vale do Mucuri, sendo um dos 13 municípios pertencentes à microrregião de Teófilo Otoni (IBGE, 2016), escolhido para o estudo de caso, por reunir as principais características dos municípios de pequeno porte que pertencem à microrregião. Para se ter uma ideia, nessa microrregião, apenas a cidade de Teófilo Otoni tem população superior a 100.000 habitantes. Em decorrência, é provável que a composição orçamentária do município escolhido seja parecida com as demais da região.

Nesses termos, a proposta deste trabalho se concentra em identificar qual o perfil orçamentário do município de Ladainha/MG, no período de 2000 a 2016, por meio da identificação da sua composição orçamentária, quanto às principais fontes de receita e 
despesas, em termos da classificação por finalidade e por natureza do gasto, como também avaliar a distribuição orçamentária, diante do que estabelecem os limites previstos na legislação vigente.

Para atingir os objetivos propostos, a segunda parte do artigo apresenta a fundamentação teórica, embasando a gestão orçamentária municipal no contexto do federalismo fiscal. Os procedimentos metodológicos, descritos na terceira parte, trazem a forma como os dados foram coletados e analisados. Na quarta parte, apresentam-se os resultados encontrados e, por último, as considerações finais quanto ao que foi proposto.

\section{Fundamentação Teórica}

\subsection{Federalismo Fiscal}

O termo federalismo, sem o adjetivo fiscal, é entendido como uma forma de organização do Estado, em que há compartilhamento de poderes políticos e constitucionais entre os diferentes níveis de governo, além da divisão das tarefas administrativas. Caracterizado pela união de regiões menores, na formação de uma unidade superior denominada Governo Central, cuja nomenclatura não significa a centralização de todo poder do Estado, mas sim a existência de um ente superior com poderes específicos e exclusivos, sob o qual estão subordinados os entes subnacionais, porém preservando a autonomia política e econômica dos seus membros (Mendes, 2004; Leroy \& Bontempo, 2017).

Em se tratando de federalismo fiscal, Silva (2005) destaca que a sua adoção por uma nação

implica distribuição de competências constitucionais fiscais entre os diferentes níveis de governo, para que cada um, de modo autônomo, e na medida de suas competências e capacidade de financiamento, possa construir desenhos institucionais capazes de disciplinar os procedimentos de contribuição e gestão tributária, transferências fiscais, composição e dimensão da despesa (Silva, 2005, p.119)

Chandra (2012) aponta que o federalismo fiscal visa compreender os fatores determinantes do grau ótimo de descentralização fiscal, os princípios que norteiam a atribuição de funções e distribuição de recursos entre governos de diferentes níveis verticais e, por fim, conceber estratégias de transferências intergovernamentais para alcançar a equidade e eficiência entre os entes federados.

Dessa forma, um importante elemento do federalismo fiscal é a descentralização, havendo diferentes razões para que ocorra esse processo, diante dos seguintes fatores: a) econômicos - representa a busca da alocação eficiente dos recursos, determinando quais bens e serviços públicos são melhor geridos de forma centralizada e quais de forma descentralizada, apontando o nível do governo que tem competência para administrar mais eficientemente; b) culturais, políticos e institucionais - nas quais a descentralização fomenta maior envolvimento dos cidadãos, demandando a transparência das ações governamentais; e c) geográficos - grandes dimensões territoriais são melhor geridas quando o poder é descentralizado entre os entes federados, em que os subnacionais, por estarem mais próximos das demandas locais, percebem-nas e atendem-nas mais facilmente que o governo central (Giambiagi; Além, 2008).

$\mathrm{O}$ processo de descentralização começou a se popularizar entre os países em desenvolvimento a partir da década de 90 , porém surgiram também problemas fiscais, muitos dos quais a literatura existente não resolve. Pelo fato desse processo ser recente nos países em desenvolvimento, as instituições necessárias para a descentralização são mais fracas, o que 
amplia nesses países, os desafios que são enfrentados pelos países desenvolvidos (Chandra, 2012).

Voltando-se ao cenário brasileiro, Giambiagi e Além (2008) corroboram afirmando que um dos problemas da descentralização presente no federalismo é a capacidade administrativa fraca de algumas unidades subnacionais pela existência de funcionários pouco qualificados, gerando a incapacidade de aproveitar ao máximo o potencial das fontes financeiras. Os autores afirmam que, numa visão ideal, a descentralização dos gastos deve vir acompanhada do aumento da capacidade de arrecadação própria dos entes subnacionais, mas por diversas razões não é isso que se observa na realidade de vários entes federados, em que muitas vezes os recursos próprios não são suficientes para o financiamento dos gastos, ocasionando a dependência de transferências intergovernamentais. Assim, os governos subnacionais que se tornam independentes pelo financiamento das ações governamentais com receitas próprias "tendem a ter maior responsabilidade fiscal, controlando melhor as suas contas e apresentando, em geral, melhores déficits do que os governos mais dependentes de transferências" (Giambiagi \& Além, 2008, p.317).

Em Estados federados, o problema das políticas fiscais vai além da preocupação da adequação da previsão das despesas e das receitas, mas também como esses componentes podem contribuir para a estabilidade econômica, a distribuição da renda e a promoção do crescimento econômico. A descentralização do poder no federalismo fiscal é de extrema relevância, porém, para ocorrer eficientemente, é necessário que as diversas responsabilidades sejam distribuídas entre os entes conforme as funções alocativas, distributivas e estabilizadoras. (Silva, 2005; Rezende, 2010).

A função alocativa está relacionada ao fornecimento de bens públicos e é um dos principais elementos da descentralização por reforçar a necessidade de autonomia entre os entes federados, buscando a maximização do bem-estar dos indivíduos no âmbito local. As funções distributivas e estabilizadoras estão associadas ao governo central, a distributiva diz respeito aos ajustes na distribuição de renda, no esforço de reduzir as desigualdades entre os entes federados, alocada como responsabilidade do governo central. Se fosse responsabilidade principalmente dos entes subnacionais em economias com grande desigualdade social, acarretaria na adoção de estratégias diferentes de distribuição de renda, que poderia suscitar movimentos migratórios para as localidades mais generosas, onerando o sistema redistributivo (Silva, 2005; Giambiagi \& Além, 2008; Rocha, Lima, \& Piacenti, 2011).

Por fim, a função estabilizadora abrange o uso da política econômica visando o alto nível de emprego, a estabilidade de preços e o crescimento econômico. A adoção de estratégias macroeconômicas para atingir esses fins fica a cargo do governo central. A função estabilizadora também pode ter participação dos governos subnacionais, no entanto sob a orientação do governo central para ter efeitos positivos. Exemplo disso é a padronização de condutas fiscais, como na LRF, que será exposta posteriormente neste artigo, aplicada a todos os níveis de governo e que objetiva a otimização das ações de política econômica orientadas à estabilização (Silva, 2005; Giambiagi \& Além, 2008).

No Brasil, a promulgação da Constituição de 1988 reforça a estrutura federalista prevendo uma maior descentralização dos níveis de governo do Estado entre União, Estadosmembro e Municípios. Dessa forma, a União perdeu parte dos seus recursos financeiros que foram destinados aos estados e municípios, o que acarretou na incorporação ao âmbito subnacional das políticas sociais, o que aumentou, principalmente nos municípios, os gastos com educação e saúde (Abrucio \& Couto, 1996). Esse processo de descentralização foi motivado por questões políticas, após anos de centralização do poder vivido no regime 
militar, necessitava-se do fortalecimento financeiro e político dos estados e municípios em detrimento do governo federal, passo essencial para a redemocratização do país (Pires, 2013).

$\mathrm{O}$ federalismo fiscal brasileiro apresenta algumas peculiaridades, destacando-se dois aspectos principais, primeiro visa minimizar as desigualdades regionais, buscando equilíbrio entre os entes federados. A segunda peculiaridade é a tendência municipalista. Com a Constituição de 1988, os municípios são reconhecidos como membros da federação em nível de igualdade com os estados no que se refere aos direitos e deveres, destacando-se a participação no sistema de transferências intergovernamentais. Tal quadro incentivou a proliferação de municípios (Giambiagi \& Além, 2008; Rezende, 2010).

Rezende (2010) aponta que essa nova etapa do federalismo fiscal brasileiro, iniciada com a Constituição de 1988, refletiu inicialmente em uma descentralização das receitas públicas para os estados e municípios, porém não foi acompanhada da descentralização das responsabilidades, provocando disparidades socioeconômicas. Com o advento do Plano Real, houve um avanço na absorção de responsabilidades sociais por parte dos estados e municípios, entretanto não alcançou o equilíbrio federativo.

Essa descentralização não refletiu no equilíbrio entre a geração de receitas e responsabilidades, existindo uma concentração de recursos públicos arrecadados na União e sobrecarga de atribuições aos municípios. Com a transferência de responsabilidades para os municípios, houve maior deslocamento de recursos do centro (nível federal) para o periférico. Esse movimento aumentou a dependência das gestões locais em relação aos entes federativos mais poderosos, principalmente pela grande desigualdade existente entre as unidades da Federação (Arretche, 1996; Pires, 2013).

Essa reestruturação do federalismo fiscal brasileiro permitiu aos municípios alçarem lugar de destaque no cenário federativo, exigindo da gestão municipal uma atuação mais profissional e adequada à legislação vigente, principalmente no âmbito orçamentário, como apresentado a seguir.

\subsection{Gestão Orçamentária Municipal}

O Orçamento Público é entendido como um instrumento de planejamento das prioridades que compõe o plano de ação do governo, usando as receitas públicas arrecadadas no financiamento dos gastos públicos, em que as escolhas revelam o perfil das decisões políticas frente à escassez de recursos (Brito \& Dias, 2012; Santos \& Camacho, 2014).

O orçamento público contemporâneo enfrenta a constante luta entre as necessidades aparentemente infinita e os recursos finitos. A urgência dos desdobramentos dificulta pensar em longo prazo e simultaneamente adaptar-se às mudanças de prioridade. Caiden (2010), ao analisar os trabalhos de Schick, aponta que os principais desafios do orçamento público é sustentar a carga futura do estado de bem-estar, redefinir os gastos públicos conforme as demandas variáveis e garantir um nível confiável de serviços públicos, mesmo tendo como preocupação precípua os compromissos existentes. Assim, hoje, elaborar um orçamento público exige do gestor compreender e analisar um ambiente desconhecido e transformador (Caiden, 2010).

No Brasil, o Orçamento Público abarca três elementos fundamentais dispostos na Constituição de 1988: o PPA, a LDO e a LOA, importantes peças do Orçamento Público de todos os entes federados. O PPA tem como função estabelecer diretrizes, objetivos e metas da administração para as despesas de capital e outras delas decorrentes, dentro do período de quatro anos. A LDO visa estabelecer os parâmetros para a alocação dos recursos no orçamento anual, a fim de garantir a realização das metas e objetos do PPA. E, por fim, a 
LOA, principal instrumento de gerenciamento orçamentário e financeiro da Administração Pública, visa administrar o equilíbrio entre receitas e despesas públicas (Nascimento \& Debus, 2001).

Outro avanço na gestão fiscal de recursos públicos é a Lei de Responsabilidade Fiscal - LRF, que estabelece normas de finanças públicas voltadas para responsabilidade na gestão fiscal. A LRF permite uma maior transparência e equilíbrio das contas públicas, exigindo uma gestão orçamentária e financeira responsável, com eficiência e eficácia, além de possibilitar o controle da sociedade sobre as ações dos governantes, com maior participação popular no direcionamento das ações para o interesse da sociedade (Matias-Pereira, 2010).

Brito e Dias (2012) ressaltam que a população exige da administração local o desenvolvimento regional, visto que, com maior autonomia sobre a arrecadação e aplicação das receitas públicas, a gestão municipal tem poder de decisão podendo interferir na realidade regional. No entanto, a maioria dos gestores não tem conhecimento para satisfazer essa necessidade. Isso tem sido amenizado com as exigências da LRF, norteando as decisões públicas.

Em estudo mais recente, Dantas et al. (2014), ao analisar a percepção dos gestores municipais quanto à utilização do orçamento público no processo de gestão na Paraíba, concluiu que o conhecimento dos gestores acerca do orçamento público é limitado, contrapondo a opinião dos pesquisados (gestores municipais) quanto ao seu conhecimento e percepção da importância do mesmo.

Para compreensão das finanças e perfil orçamentário municipal, faz-se necessário, além da estruturação do orçamento público municipal, conhecer os componentes do orçamento, as receitas e despesas municipais e suas formas de classificação.

\subsection{Receitas Públicas Municipais}

A definição de receita pública remete ao ingresso de recursos financeiros nos cofres do Estado, utilizados para financiamento das despesas públicas com objetivo de suprir as demandas sociais. Estas são registradas como receitas orçamentárias, que

são disponibilidades de recursos financeiros que ingressam durante o exercício e que aumentam o saldo financeiro da instituição. Instrumento por meio do qual se viabiliza a execução das políticas públicas, as receitas orçamentárias são fontes de recursos utilizadas pelo Estado em programas e ações cuja finalidade precípua é atender às necessidades públicas e demandas da sociedade (MCASP, 2016, p.36).

As receitas orçamentárias públicas, seguindo o critério definido por Rezende (2010), podem ser classificadas de acordo com três abordagens: captação de recurso, origem dos recursos e orçamento a que estão vinculadas. Neste estudo, focou-se na classificação quanto à captação e origem dos recursos.

Quanto à captação dos recursos, as receitas podem ser próprias ou de transferências. As receitas próprias são as arrecadadas pelo município por meio dos tributos. Ou seja, "toda prestação pecuniária compulsória, em moeda ou cujo valor nela se possa exprimir, que não constitua sanção de ato ilícito, instituída em lei e cobrada mediante atividade administrativa plenamente vinculada", conceito presente no Código Tributário Nacional em seu art. $3^{\circ}$. O tributo pode ser subdivido em impostos, taxas e contribuições de melhoria. No contexto do município, os impostos arrecadados são: Imposto Predial e Territorial Urbano (IPTU), Imposto de Renda Retido na Fonte (IRRF), Imposto sobre a Transmissão Onerosa Inter Vivos 
de Bens Imóveis e Direitos a ele Relativos (ITBI) e Imposto sobre Serviços de Qualquer Natureza (ISSQN) (Rezende, 2010; Brito \& Dias, 2012).

A outra forma de captação dos recursos são as receitas de transferências, ou transferências intergovernamentais, que são os repasses de partes dos recursos arrecadados dos entes superiores para os subnacionais. Nesse caso, constitui as transferências da união para os estados e municípios e as dos estados para os municípios. As transferências intergovernamentais cumprem os objetivos da função distributiva a fim de assegurar que municípios, em que capacidade de arrecadação própria é insuficiente, possam atender as demandas da população (Rocha, Lima, \& Piacenti, 2011).

O Quadro 1 apresenta o resumo das principais fontes de receitas municipais proposto por Santos e Santos (2014). Pode-se verificar, além das receitas próprias apresentadas anteriormente, as transferências intergovernamentais do estado e da União, descrevendo o fato gerador e a parcela de transferência.

Na classificação quanto à origem dos recursos, as receitas orçamentárias são divididas em receitas correntes e receitas de capital. As receitas correntes são arrecadadas dentro do exercício financeiro, são instrumentos para financiar os objetivos dos programas e ações orçamentárias e satisfazer finalidades públicas. Já as receitas de capital são as de fluxo não regulares ou que estejam ligadas às despesas de capital (Rezende, 2010; MCASP, 2016).

\begin{tabular}{|c|c|c|c|}
\hline & TIPO & FATO GERADOR & TRANSFERÊNCIA \\
\hline \multirow{5}{*}{ 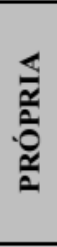 } & ISS & $\begin{array}{l}\text { A prestação por empresa ou profissional autônomo de serviço } \\
\text { constante da lista (CTN). }\end{array}$ & \multirow{5}{*}{$\begin{array}{l}100 \% \text { do total arrecadado no } \\
\text { próprio município. }\end{array}$} \\
\hline & IPTU & A propriedade, o domínio útil ou a posse de bens imóveis. & \\
\hline & ITBI & A transmissão de bens inter-vivos. & \\
\hline & Taxas & Custear os serviços disponíveis a sociedade. & \\
\hline & Contribuições & Decorrente de obras públicas. & \\
\hline \multirow{2}{*}{ 文 } & ICMS & $\begin{array}{l}\text { A saída e a entrada de mercadorias em estabelecimentos comercial, } \\
\text { industrial ou produtor. }\end{array}$ & $\begin{array}{l}25 \% \text { da arrecadação no } \\
\text { município. }\end{array}$ \\
\hline & IPVA & A propriedade de veículos automotores. & $\begin{array}{l}50 \% \text { da arrecadação no } \\
\text { município }\end{array}$ \\
\hline \multirow{8}{*}{$\underset{\substack{\frac{1}{2} \\
\frac{1}{2}}}{\frac{1}{x}}$} & \multirow[t]{2}{*}{ FPM (IR+IPI) } & $\begin{array}{l}\text { (IR) Toda renda proveniente do rendimento do capital, do trabalho ou } \\
\text { de ambos, e todo acréscimo ao patrimônio das pessoas físicas ou } \\
\text { jurídicas. }\end{array}$ & \multirow[t]{2}{*}{$23,5 \%$ de IPI+IR(líquido). } \\
\hline & & (IPI) Produção que sai do estabelecimento industrial. & \\
\hline & IPI- exportação & Ressarcimento aos estados exportadores & $\begin{array}{l}25 \% \text { aos municípios que se } \\
\text { localizam em estados e } \\
\text { exportadores. }\end{array}$ \\
\hline & FEX & Auxílio financeiro de estímulo as exportações (eventual) & $25 \%$ aos municípios. \\
\hline & Cide & $\begin{array}{l}\text { Contribuição que incide sobre importação e comercialização de } \\
\text { combustiveis. }\end{array}$ & $\begin{array}{c}\text { Dos } 25 \% \text { transferidos aos } \\
\text { Estados, } 25 \% \text { são repassados } \\
\text { para os municípios } \\
\end{array}$ \\
\hline & ITR & $\begin{array}{l}\text { Propriedade, o domínio útil ou a posse de imóvel localizado fora da } \\
\text { zona urbana do Município }\end{array}$ & $\begin{array}{l}50 \% \text { ou } 100 \% \text { (por meio do } \\
\text { Convênio ITR). }\end{array}$ \\
\hline & CFEM & Utilização econômica pela exploração de recursos minerais & $\begin{array}{c}65 \% \text { da arrecadação no } \\
\text { município. }\end{array}$ \\
\hline & Royalties & $\begin{array}{l}\text { Destinados à indenização dos Estados e dos Municípios pelos danos } \\
\text { econômicos, sociais e ecológicos causados pela atividade de } \\
\text { exploração do petróleo }\end{array}$ & $\begin{array}{l}20 \% \text { para os municípios não } \\
\text { produtores e } 17 \% \text { para } \\
\text { municípios produtores }\end{array}$ \\
\hline
\end{tabular}

Quadro 1: Resumo das Principais Fontes de Receitas Municipais.

Fonte: Santos; Santos (2014, p.11). 


\subsection{Despesas Públicas Municipais}

Despesa pública pode ser definida como o conjunto de dispêndios realizados pelos entes públicos para o funcionamento e manutenção dos serviços públicos, entendida também como todo esforço despendido pela Administração Pública para assegurar o bom funcionamento da máquina administrativa. As despesas públicas podem ser classificadas quanto à natureza, quanto à finalidade das despesas e quanto ao agente encarregado da execução do gasto. Neste trabalho, focou-se na classificação quanto à finalidade e quanto à natureza (Rezende, 2010; Santos \& Camacho, 2014; MCASP, 2016).

Quanto à natureza, as despesas, assim como as receitas, são classificadas em duas categorias econômicas: despesas correntes e despesas de capital. As despesas correntes são "as despesas que não contribuem, diretamente, para a formação ou aquisição de um bem de capital” (MCASP, 2016, p.74). Já as despesas de capital contribuem diretamente para a aquisição desse bem.

$\mathrm{Na}$ classificação quanto à finalidade, as despesas são categorizadas por funções e subfunções voltadas pela determinação das áreas em que serão empregados os recursos públicos. Nessa classificação, atualmente são registradas 28 funções a que se destina o financiamento dos gastos municipais. No entanto, focalizou-se neste estudo os denominados gastos sociais que representam os maiores dispêndios municipais, permitindo uma análise centrada na atuação dos municípios dentro das políticas sociais. São gastos sociais: educação e cultura, saúde e saneamento, assistência e previdência, habitação e urbanismo e segurança pública. (Rezende, 2010; Brito \& Dias, 2012; MCASP, 2016).

Ao tratar de despesas públicas e ao analisar a Gestão Orçamentária Municipal, é necessário considerar as determinações legais quanto ao Orçamento Público. Deve-se atentar aos limites que são estabelecidos a fim de desestimular os desvios de recursos públicos. Dentre os principais limites legais para o âmbito municipal, têm-se os definidos na Constituição de 1988 , no seu art. 212 , que prevê aplicação mínima de $25 \%$ da arrecadação para a educação.

A União aplicará, anualmente, nunca menos de dezoito, e os Estados, o Distrito Federal e os Municípios vinte e cinco por cento, no mínimo, da receita resultante de impostos, compreendida a proveniente de transferências, na manutenção e desenvolvimento do ensino (BRASIL, 1988).

Assim como na educação, na saúde a Constituição de 1988 no Título X, art. 77, inciso III, estabeleceu uma aplicação não inferior a $15 \%$ da arrecadação para dispêndio com saúde nos municípios. A LRF também estabeleceu limites para a gestão fiscal dos municípios, nesse caso, quanto às despesas totais com pessoal, fixando que essa não poderá ultrapassar $60 \%$ das receitas correntes líquidas, sendo repartidos 6\% para o Legislativo e 54\% para o Executivo.

Em 15 de dezembro de 2016, foi aprovada a Emenda constitucional $\mathrm{n}^{\circ}$ 95, conhecida como a Proposta de Emenda à Constituição (PEC) do teto dos gastos públicos, que estabeleceu novos limites para as despesas públicas por vinte exercícios financeiros para a despesas primárias e revisão das aplicações mínimas para os serviços públicos de saúde e em manutenção e desenvolvimento do ensino. Não há reflexos dessa legislação neste estudo, visto que sua incidência se dará a partir dos exercícios financeiros de 2018. 


\subsection{Perfil Orçamentário do Município}

Para uma melhor compreensão do perfil orçamentário, foi realizado um levantamento dos principais estudos que abordaram a temática. São comuns estudos que analisem apenas as receitas ou apenas as despesas, não sendo encontrados trabalhos que apontem ambas as análises.

Dentre os estudos que analisam as receitas, está o de Pereira (2002), que estudou a relação entre as receitas transferidas e as receitas próprias dos municípios do Rio Grande do Sul, no período de 1989 a 1998, a fim de considerar sobre as transformações ocorridas nas finanças públicas municipais. Depreendeu que, conforme aumentavam as transferências intergovernamentais, houve uma tendência à redução das receitas próprias, ocorrendo casos em que municípios dependiam exclusivamente das receitas de transferência. Dentre os problemas identificados na arrecadação de tributos, percebe-se a falta de capacidade técnica dos municípios para a fiscalização e arrecadação e falta de recursos humanos e vontade do poder local em arrecadar com eficiência.

Brito e Dias (2012), ao analisar o comportamento das receitas próprias e transferências intergovernamentais do município de Parnaíba/PI, observaram um crescimento na arrecadação do período analisado (2003 a 2012). Nas receitas próprias, o ISSQN é o tributo que tem maior representatividade média no período $\mathrm{e}$, quanto às transferências intergovernamentais, a que tem maior parcela é o Fundo de Participação dos Municípios (FPM). De maneira geral, o município nutre uma dependência financeira dos entes federados superiores sendo que, da sua arrecadação média no período, mais de $90 \%$ corresponde às transferências intergovernamentais, sendo esse valor 12 vezes maior que as receitas próprias.

Santos e Santos (2014), diferentemente dos outros estudos, propuseram-se a analisar a relevância do FPM para os municípios do sul da Bahia e sua dependência em relação a este. Verificaram que os pequenos municípios têm um alto grau de dependência das transferências intergovernamentais e isso se dá principalmente por possuírem uma pequena população, baixa capacidade arrecadatória, atividade econômica pouco expressiva; também são basicamente rurais e têm a prefeitura como o maior empregador. Esse cenário se difere dos municípios maiores, com forte atividade industrial, pois são mais estruturados economicamente e, por isso, menos dependentes.

Nos estudos de Ferreira et al (2016), os autores concentraram-se em analisar as receitas próprias do município de Contagem/MG, no período de 2000 a 2014, e verificaram que as receitas próprias são a menor parcela na arrecadação total do município, sendo este dependente de transferências intergovernamentais. No entanto, no período, observou-se um aumento da participação percentual da receita própria na receita total e, por consequência, uma queda das transferências intergovernamentais.

Assim como nos trabalhos anteriores, Leroy e Bontempo (2017), em seu estudo, analisaram as receitas, entretanto focaram na classificação quanto à origem dos recursos, mais especificamente nas receitas correntes do pequeno município de Rio Paranaíba/MG. Obtiveram um resultado semelhante aos anteriores com a baixa arrecadação própria e dependência das transferências intergovernamentais.

Abordando as despesas, foi encontrado o trabalho de Silva e Damacena (2012), que se propuseram a analisar as despesas correntes no município de João Pessoa/PB, no período de 2006 a 2010. Depreenderam que, nesse período, houve o crescimento desses gastos e essa classificação ocupou a maior parcela dos gastos do município, entretanto foram respeitados os limites previstos na LRF e na LOA. 
No que tange aos gastos sociais, Santos e Andrade (2014), ao analisar a similaridade do comportamento das funções sociais nas cidades polos de Minas Gerais, observaram que, entre as cidades com população até 105 mil habitantes, os gastos sociais com habitação, cultura, assistência social e previdência social permaneceram estáveis; a função Urbanismo teve queda e depois crescimento e o Saneamento permaneceu estável, depois teve uma retração. Cabe ressaltar que os gastos sociais com Saúde e Educação são os mais elevados entre a categoria.

Em estudo semelhante, Rocha, Lima e Piacenti (2011) analisaram a evolução dos recursos públicos disponíveis e sua alocação em gastos sociais nos municípios da região sul do país. Depreenderam que, nos municípios entre 10.001 e 50.000 habitantes, investimentos estão concentrados em Educação e Cultura seguidos de Saúde e Saneamento; abaixo de 10\% de participação nos gastos, estão Habitação e Urbanismo, Assistência e Previdência e Segurança Pública.

Nota-se um crescimento nos estudos que visam compreender a realidade orçamentária municipal, mais especificamente em pequenos municípios, em que se verifica a similaridade de situação como a dependência financeira, baixa arrecadação própria e o foco nos gastos sociais com Educação e Saúde.

\section{Método de Pesquisa}

Esta pesquisa orientou-se pela abordagem quantitativa, visando identificar qual o perfil orçamentário do município de Ladainha/MG, no período de 2000 a 2016. Segundo Zanella (2009), a pesquisa quantitativa caracteriza-se pelo uso de instrumentos estatísticos e tem como finalidade medir as relações entre as variáveis, apresentando uma preocupação com a representatividade numérica.

Por focar na realidade do município de Ladainha/MG, essa investigação pode ser caracterizada estudo de caso, definido por Yin (2001, p.32) como uma "investigação empírica que investiga um fenômeno contemporâneo dentro do seu contexto da vida real, especialmente quando os limites entre fenômeno e contexto não estão claramente definidos". Esse município tem uma população estimada de 18.066 habitantes e área da unidade territorial de $866,290 \mathrm{~km}^{2}$. Emancipado no ano de 1948, é caracterizado principalmente pelo grande potencial para exploração da agropecuária, visto que aproximadamente $74,63 \%$ da população reside em área rural. No entanto, é a prestação de serviços que possibilita maior valor adicionado no PIB do município (IBGE, 2017; Ladainha, 2017).

No tocante aos procedimentos, a pesquisa se classifica como bibliográfica e documental. Utilizou-se de livros e artigos científicos para o embasamento teórico da análise e dados secundários coletados nas bases da Secretaria do Tesouro Nacional (STN) e da Finanças do Brasil (FINIBRA), compreendendo os anos de 2000 a 2015; e do Tribunal de Contas do Estado de Minas Gerais (TCE/MG), por meio do portal Fiscalizando com o TCE coletou-se os dados ano de 2016. Diferentemente dos anos anteriores, cujos dados correspondem às receitas arrecadadas e às despesas pagas, no ano de 2016, utilizou-se as receitas previstas e despesas fixadas na LOA, por não estarem disponíveis até o momento da coleta dos dados, servindo, assim, como base para uma comparação temporal.

Tomaram-se, como série histórica, os dados de 2000 a 2016, no intuito de abarcar a nova estruturação orçamentária do país, influenciada principalmente pela instituição da LRF no ano 2000, bem como abranger um horizonte temporal considerável para coleta e análise dos dados. No período, verifica-se o último ano do mandato de 1997-2000 e cinco mandatos completos até o ano de 2016. Ressalta-se que os valores foram atualizados pelo Índice Geral 
de Preços - Disponibilidade Interna (IGP-DI/FGV), tomando como base o ano de 2016 para ajustar os preços correntes.

Após coletados e deflacionados, os dados foram analisados quantitativamente para identificar a composição orçamentária do município, verificando as principais classificações de receitas e despesas, em uma análise vertical (composição em relação ao total) e análise horizontal (variação no tempo). Para isto, utilizou-se de estatística descritiva básica, por meio de média simples, cálculos de variação e taxa de crescimento. Para facilitar a compreensão, os dados foram apresentados em gráficos e tabelas.

\section{Análise dos Resultados}

A análise dos resultados obtidos é realizada e apresentada de forma a descrever o perfil orçamentário do Município de Ladainha, tal como se propõe no início deste trabalho. Destarte, o conteúdo dessa seção está organizado da seguinte forma: a análise das receitas orçamentárias, das despesas orçamentárias e, por fim, o delineamento do perfil orçamentário. Primeiramente, analisaram-se as receitas e despesas, a partir da proposta apresentada.

No que diz respeito à composição orçamentária, é possível observar (Gráfico 1) a evolução das receitas orçamentárias do município de Ladainha de 2000 a 2016, verificando-se o crescimento do total de receitas do município, no decorrer dos anos, como reforça a linha de tendência traçada no gráfico, convergindo em um crescimento de $121,95 \%$ ao se comparar os anos de 2000 e $2015^{1}$. Nota-se redução da arrecadação, em comparação com o ano anterior, apenas em $2003(32,37 \%), 2015(0,03 \%)$ e 2016 (6,98\%), porém não comprometeu o crescimento identificado no horizonte temporal da pesquisa.

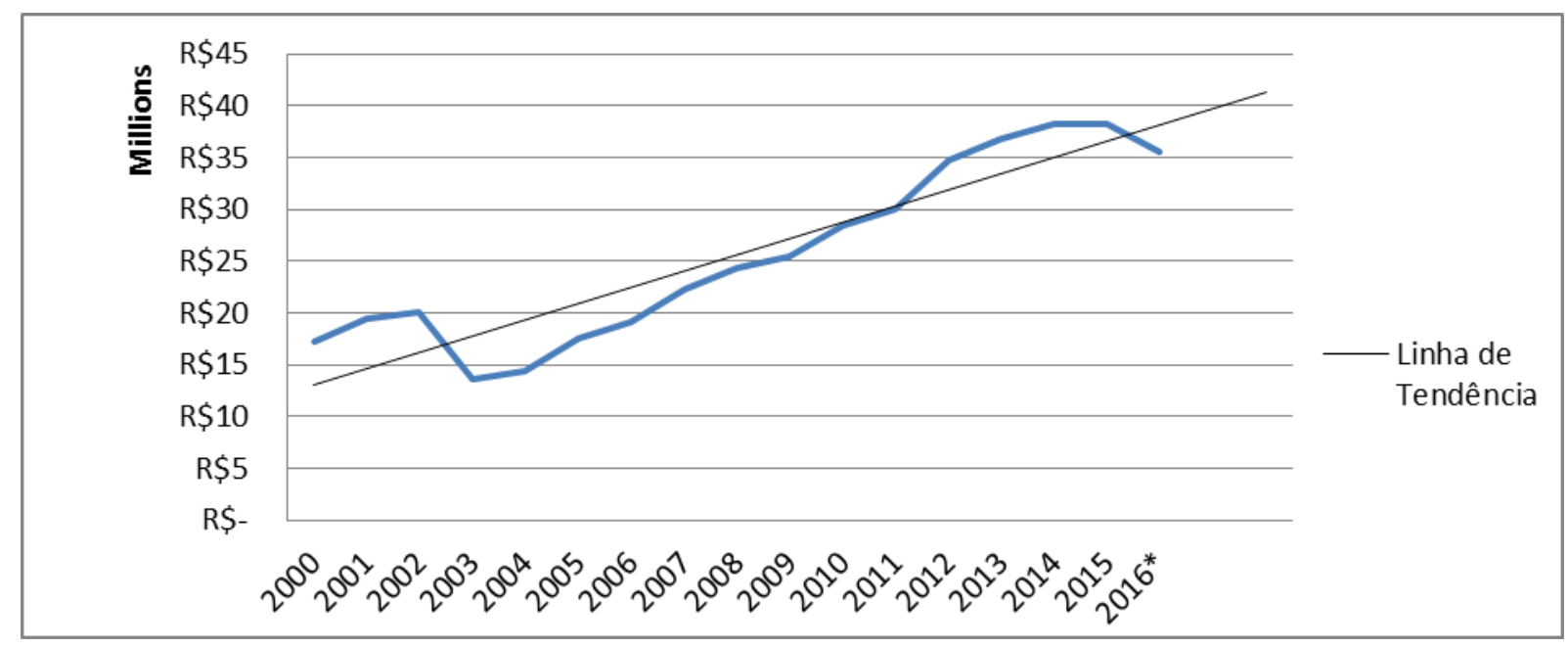

Gráfico 1 Receitas Orçamentárias de 2000 a 2016.

Fonte: Dados da pesquisa.

$\mathrm{Na}$ classificação quanto à origem das receitas, têm-se as receitas correntes e receitas de capital, como mostra o Gráfico 2. As receitas correntes representam a maior parcela das receitas orçamentárias, representando em média 94,22\% do total arrecadado, considerando o valor após a subtração das deduções das receitas correntes. As receitas de capital correspondem em média 5,78\%, depreendendo que a tendência de crescimento vista no gráfico anterior deu-se principalmente às receitas correntes. 


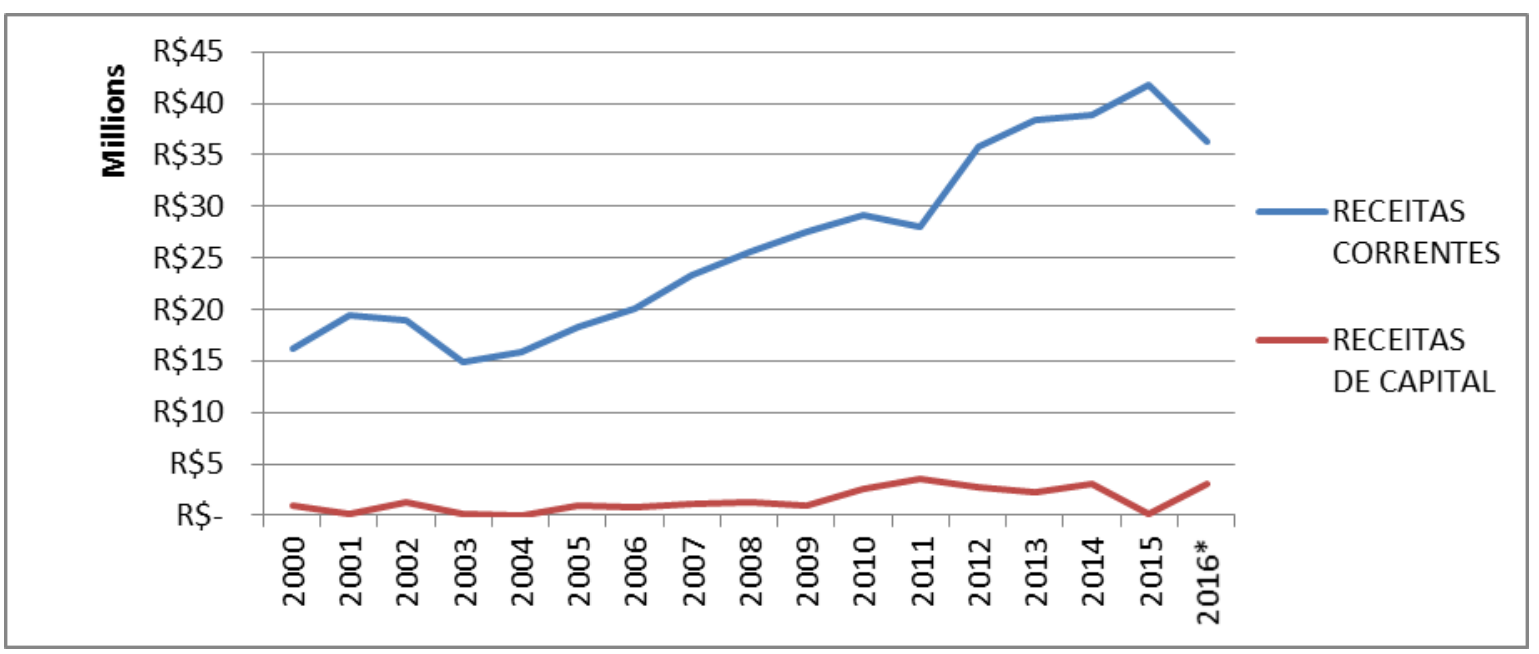

Gráfico 2: Evolução das Receitas Correntes e Receitas de Capital.

Fonte: Dados da pesquisa.

Quanto à classificação por desdobramento da receita corrente, analisando o perfil de arrecadação do município de Ladainha, verifica-se que as receitas tributárias representam em média $2,03 \%$, havendo um crescimento de apenas $6 \%$ do ano de 2002 a $2015^{\text {ii }}$. Analisando as demais receitas, a receita de serviços representa em média $2,42 \%$, as receitas de contribuições e receitas patrimoniais representam em média $0,52 \%$ e $0,48 \%$ respectivamente. Quanto à receita agropecuária, identificou-se somente arrecadação no ano de 2011, no valor de $\mathrm{R} \$ 1.108,79$.

Nota-se, portanto que é baixa a participação das receitas tributárias em relação ao total da receita orçamentária arrecadada pelo município. Dessa forma, tais receitas são insuficientes para atender às demandas da população. Como visto no trabalho de Leroy e Bontempo (2017), sobre a realidade do município de Rio Paranaíba/MG, essa situação é comum entre municípios pequenos que tendem a depender das Transferências Intergovernamentais. Podese considerar que a baixa participação dessas receitas e, principalmente, da receita tributária é reflexo da dificuldade da Gestão Municipal em fiscalizar a arrecadação dos tributos (Pereira, 2002; Santos; Santos, 2014; Brito; Dias, 2015; Leroy; Bontempo, 2017).

Dentre os tributos arrecadados pelo município, os que mais impactam nas receitas próprias são os impostos (Gráfico 3). No município de Ladainha, os de maior representatividade são o IRRF e o ISSQN, o que reforça a caracterização do município cujo maior valor adicionado do PIB vem da Prestação de Serviços. Como aproximadamente 75\% da população residem em área rural, o IPTU tem uma parcela mínima nas receitas próprias, o que também pode ser justificado pela observação de Abrucio e Couto (1996), por este ser um imposto direto e facilmente percebido pela população, há uma tendência a mantê-lo num nível baixo para não interferir na popularidade do Gestor Municipal. 


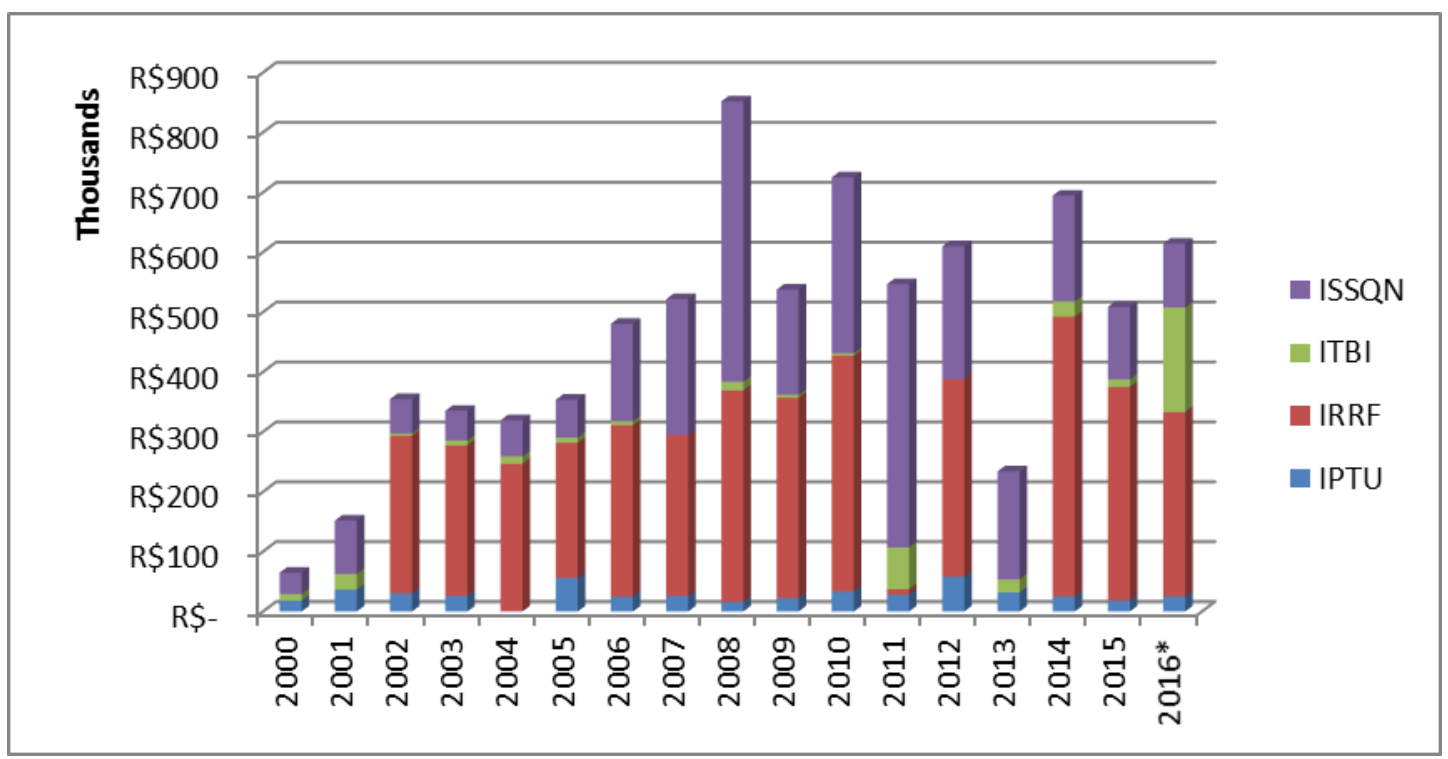

Gráfico 3: Impostos Arrecadados por ano (2000 a 2016).

Fonte: Dados da pesquisa.

No ano de 2016, verificou-se um aumento na previsão da arrecadação do ITBI, o que só pode ser confirmado com a comparação das receitas previstas e as receitas executadas.

As receitas de transferências intergovernamentais, como se observa no Gráfico 4, representam a maior parcela de arrecadação do município das receitas orçamentárias, representando em média $88,81 \%$. Isso reforça a dependência do município de Ladainha em relação aos entes federados superiores e corrobora as afirmações dos autores Giambiagi e Além (2008) e o resultado dos estudos de Pereira (2002), Brito e Dias (2012), Santos e Santos (2014), Ferreira et al (2016) e Leroy e Bontempo (2017).

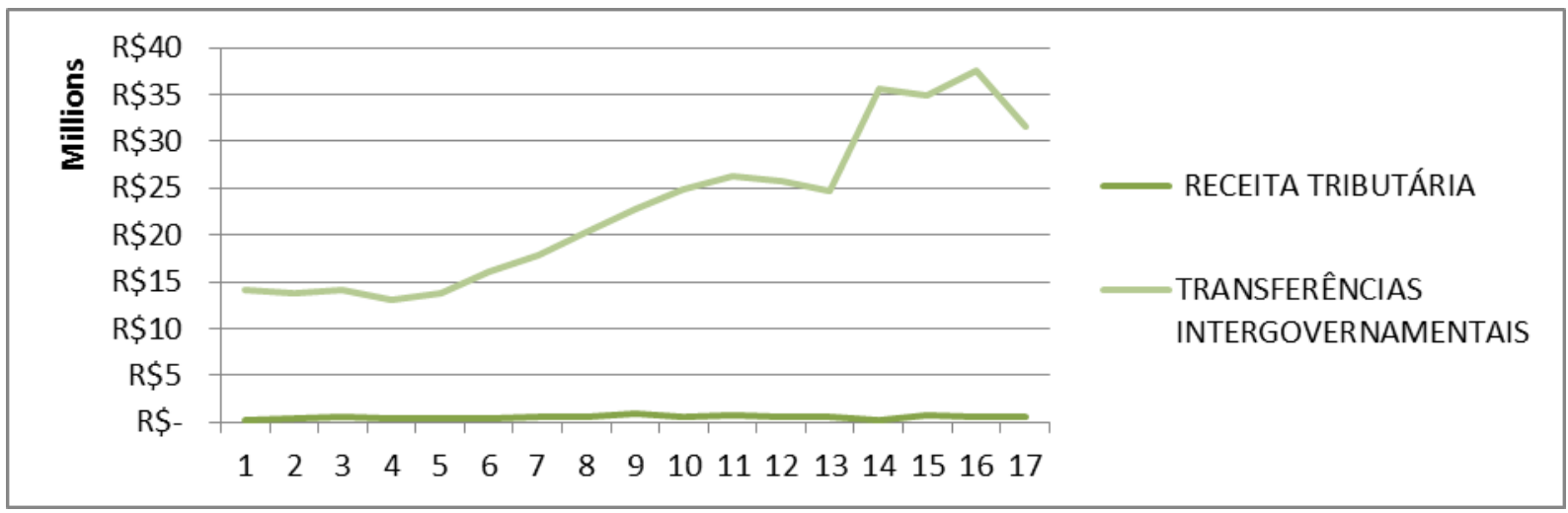

Gráfico 4: Evolução das Receitas Tributárias e Transferências Intergovernamentais.

Fonte: Dados da pesquisa.

Analisando as transferências intergovernamentais, observa-se, conforme mostra o Gráfico 5, um crescimento do valor das transferências no decorrer dos anos, sendo que a maior parcela de transferências recebidas pelo município de Ladainha é oriunda da União, havendo também transferências regulares do estado e multigovernamentais em parcelas menores. Já as transferências por parte de municípios aparecem somente no ano de 2011, não sendo um recurso regular para o município, o que pode ser justificado pela gestão consorciada 
ou compartilhada de resíduos sólidos fundamentada na Lei $\mathrm{n}^{\circ}$ 12.305, de agosto de 2010, que institui a Política Nacional de Resíduos Sólidos.

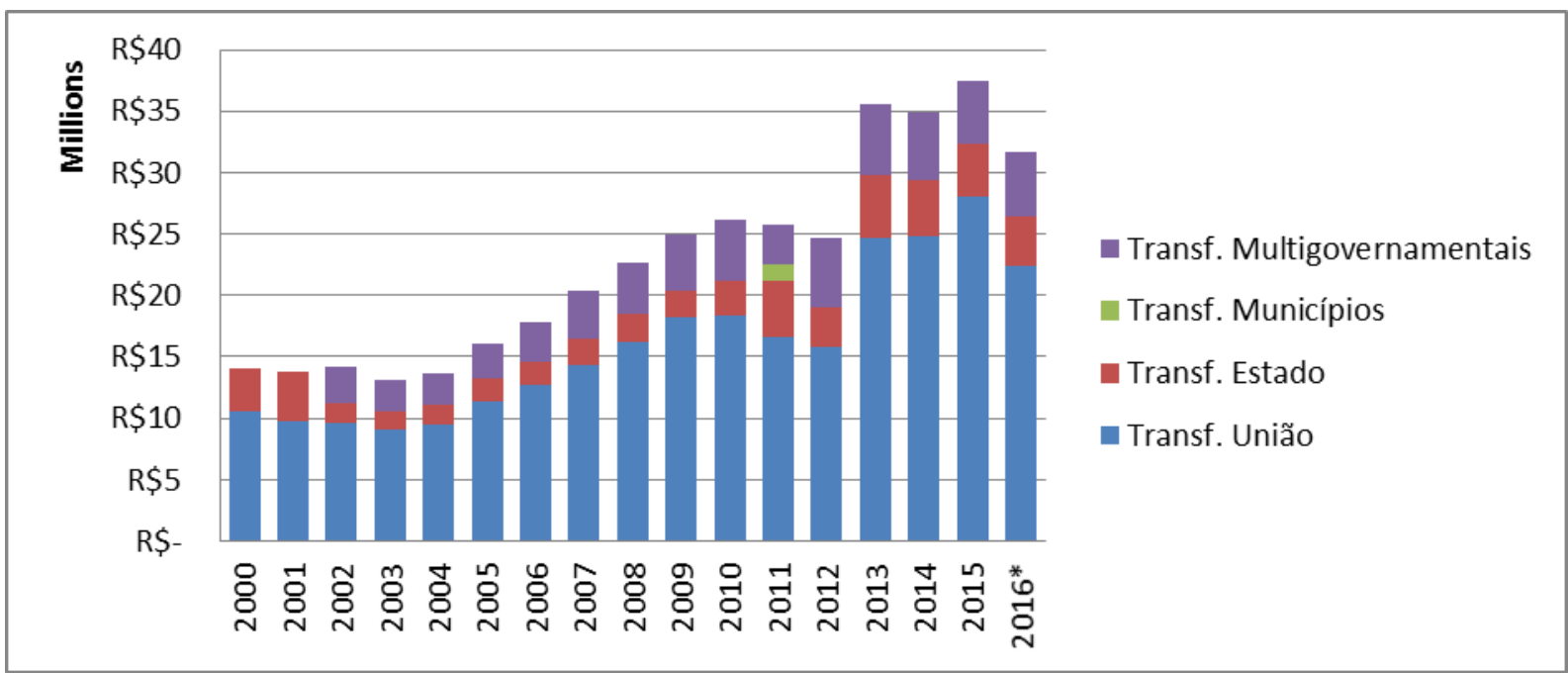

Gráfico 6: Transferências Intergovernamentais por ano (2000 a 2016).

Fonte: Dados da pesquisa.

Como visto no gráfico anterior, as transferências da União representam a maior parcela de transferências recebidas pelo município estudado. Destaca-se a Cota do Fundo de Participação dos Municípios repassada pela União que representa em média 50,13\% do total de receitas do município, seguida pelo repasse do Sistema Único de Saúde (SUS) União, com média de 7,34\%. As demais transferências têm baixa participação na composição (Gráfico 6).

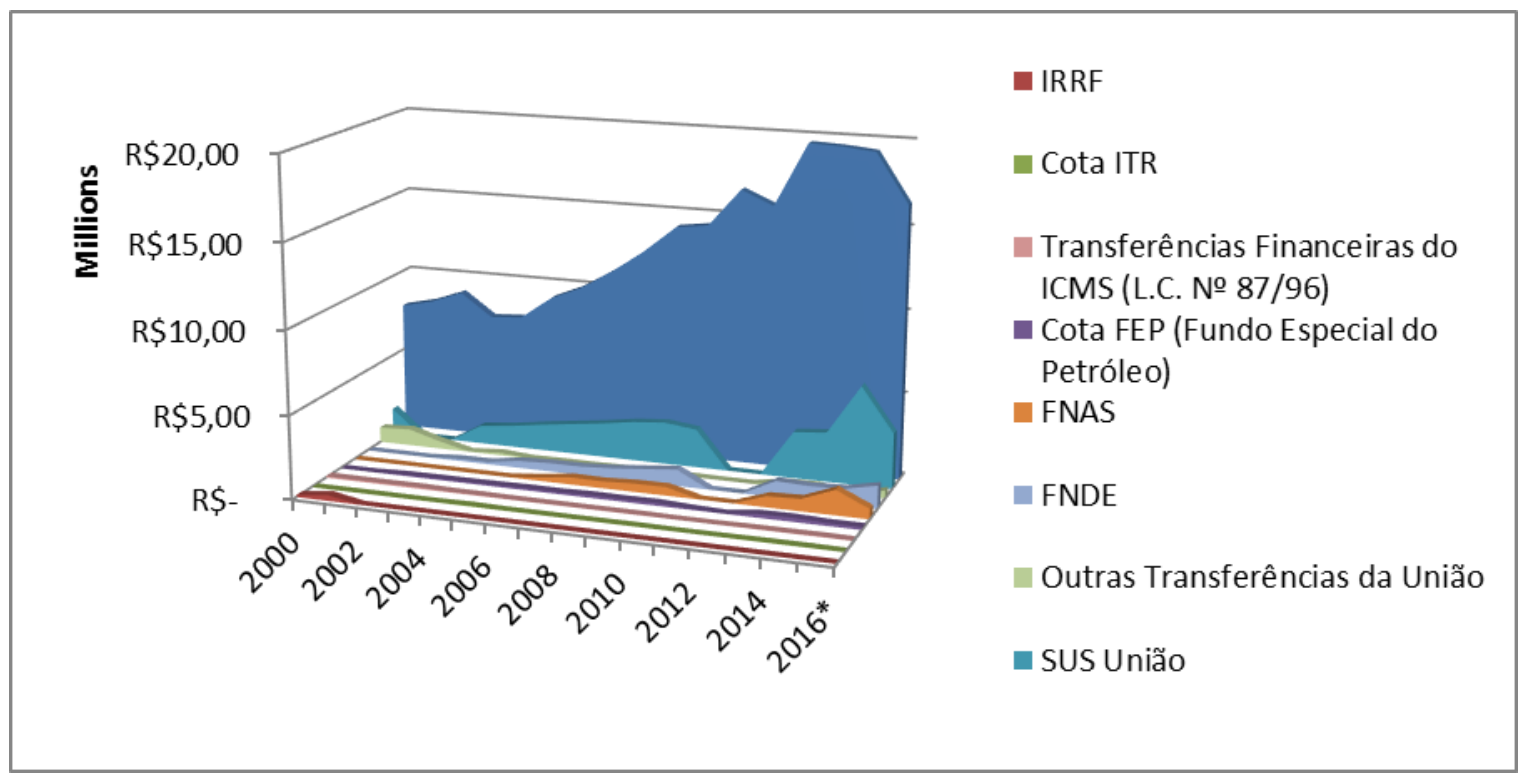

Gráfico 5: Transferências Intergovernamentais da União.

Fonte: Dados da pesquisa.

Considerando as Transferências do Estado recebidas pelo município de Ladainha, observa-se um aumento no decorrer dos anos, sendo que o mais expressivo é a Cota do Imposto sobre Circulação de Mercadorias e Serviços (ICMS), seguida pela Cota do Imposto sobre Propriedade de Veículos Automotores (IPVA) e por outras transferências do Estado (Gráfico 7). 


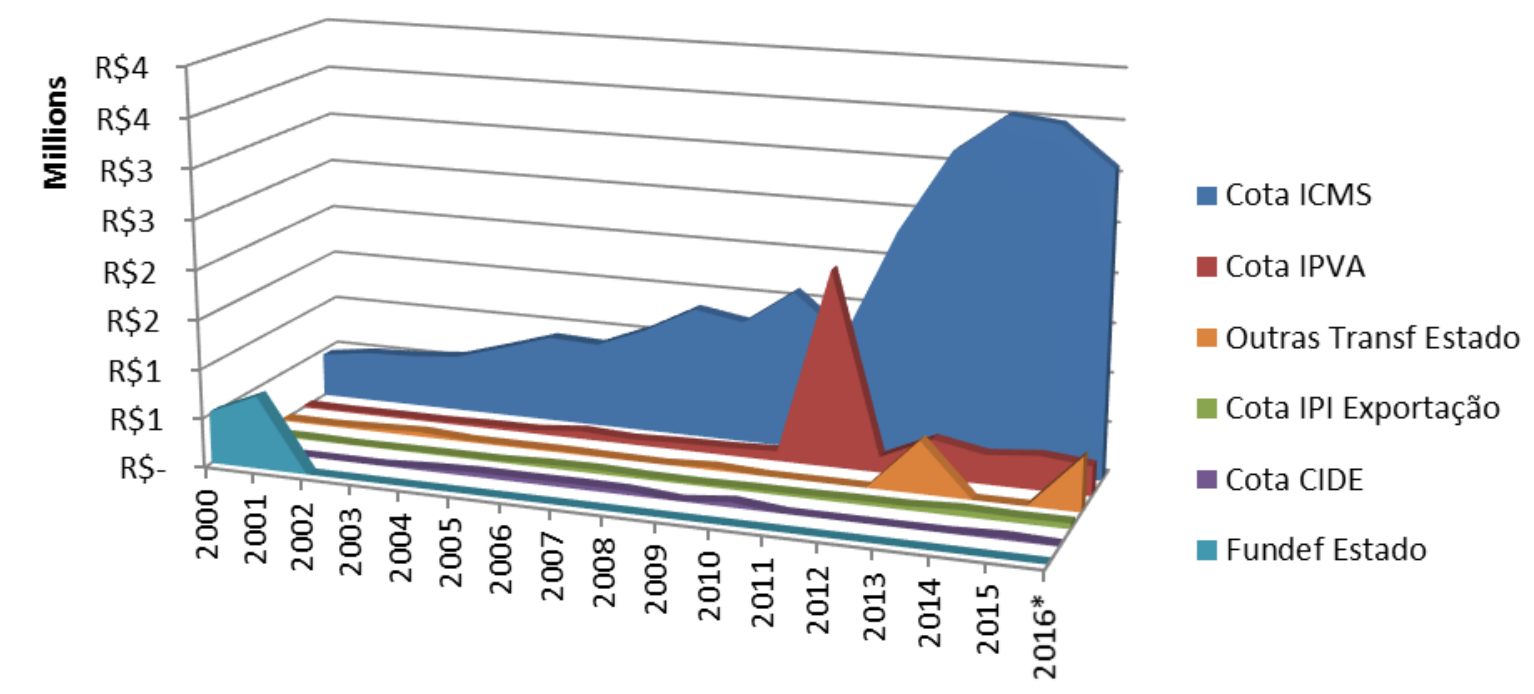

Gráfico 7: Transferências Intergovernamentais do Estado.

Fonte: Dados da pesquisa.

A Cota ICMS representa o maior valor recebido, exceto nos anos de 2000 e 2001, em que o maior valor decorria do FUNDEF Estado e em uma situação atípica no ano de 2011, no qual o maior valor recebido foi referente à Cota IPVA, que pode ser justificado com o aumento em $10 \%$ da frota de veículos no Estado de Minas Gerais (SEF-MG, 2012). As demais transferências não têm grande representatividade no total das transferências do Estado.

Com essas análises sobre as receitas orçamentárias do município de Ladainha, no período de 2000 a 2016, depreende-se que houve um crescimento das receitas orçamentárias para o atendimento das demandas por serviço. Dessas receitas orçamentárias, as receitas correntes são as de maior participação, não havendo grandes variações das receitas de capital. $\mathrm{Na}$ classificação quanto à captação de receitas, verifica-se uma grande dependência do município de recursos externos, sendo os recursos de arrecadação tributária insuficiente para suprir as necessidades da população. As principais transferências recebidas pelo município são a cota do FPM, oriunda da União, e a cota do ICMS, remetida pelo Estado. Tal perfil é corroborado pelos estudos de Santos e Santos (2014), nos quais os municípios de pequeno porte do Sul da Bahia apresentaram alto grau de dependência, principalmente por possuírem economia pouco expressiva focada na atividade agrícola. E também nota similaridade com o estudo de Leroy e Bontempo (2017), no qual o FPM e o ICMS são as transferências com maior representatividade para o município.

A análise do perfil orçamentário do município não se baseia somente nas receitas, sendo necessário compreender também as despesas para que esse perfil se complete. Quanto às despesas orçamentárias do município, pode-se verificar que, assim como as receitas orçamentárias, houve um crescimento no decorrer dos anos, como mostra a linha de tendência traçada no Gráfico 8. Na análise horizontal, constatou-se que as despesas orçamentárias elevaram em 95,96\% no período entre os anos 2000 e 2015. 


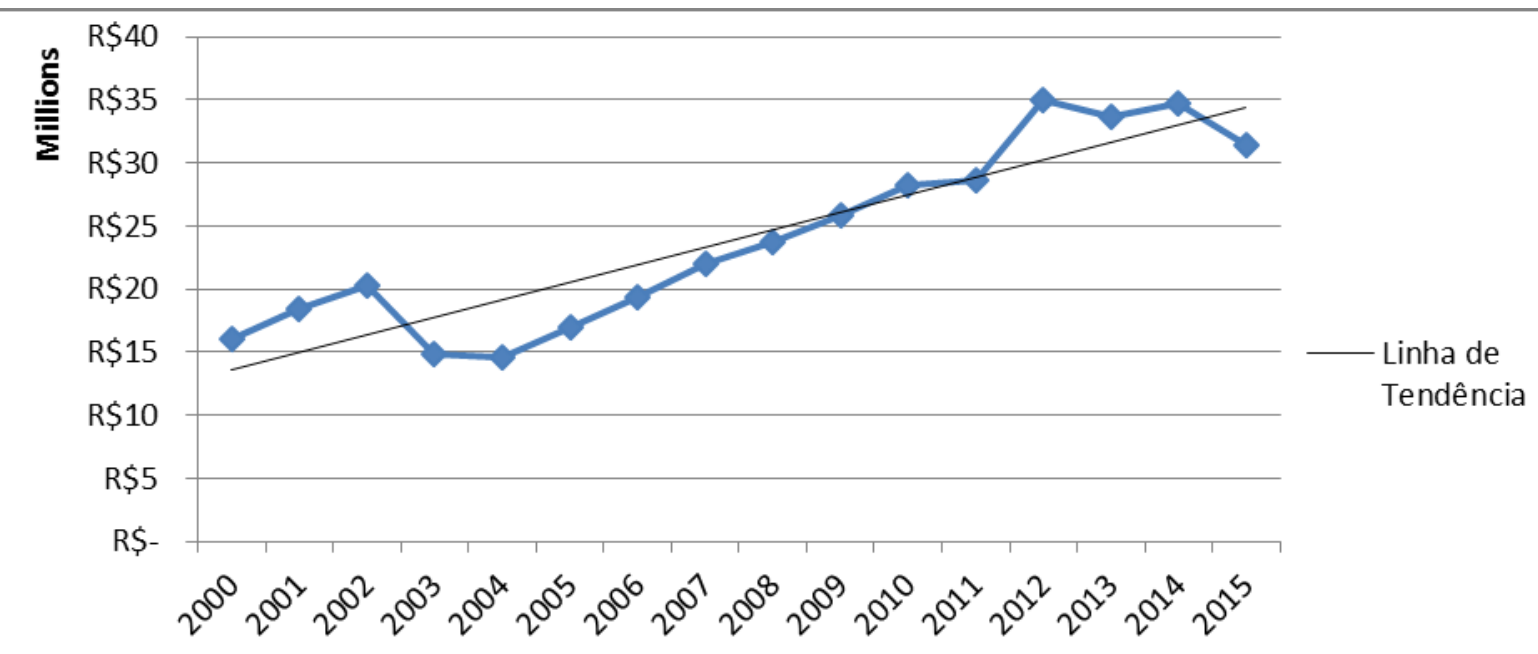

Gráfico 9: Despesas Orçamentárias de 2000 a 2015.

Fonte: Dados da pesquisa.

Considerando a classificação quanto à natureza das despesas, pode-se destacar as despesas correntes e as despesas de capital. No município de Ladainha, há uma concentração das despesas na categoria corrente havendo um crescimento de 107,48\% de 2000 a 2015 . Tal categoria foi a mais impactante para o crescimento das despesas orçamentárias, como pode ser visto no Gráfico 9. No entanto, as despesas de capital tiveram um leve crescimento de $24,35 \%$ na comparação com o mesmo período. Nota-se, ainda, no Gráfico 9, que houve elevação das despesas de capital no ano 2012, com pico em 2013, ocasionando a queda das despesas correntes do ano. Esse quadro também é verificado na pesquisa de Silva e Damacena (2012), que identificou o crescimento dos gastos influenciado principalmente pelo crescimento das despesas correntes.

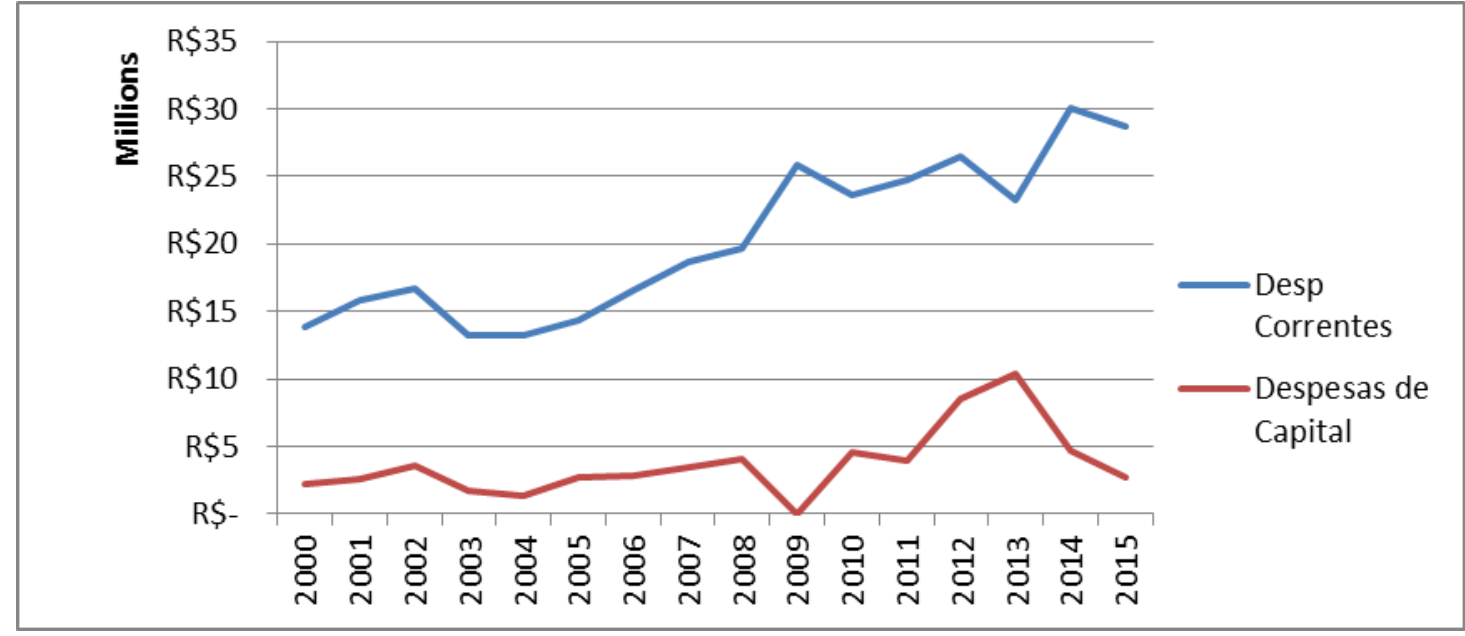

Gráfico 8: Evolução das Despesas Correntes e Despesas de Capital.

Fonte: Dados da pesquisa.

Considerando a classificação quanto à finalidade das despesas, este estudo focou nos gastos sociais que compreendem a educação e cultura, saúde e saneamento, habitação e urbanismo, assistência e previdência, e segurança pública. No Gráfico 10, verifica-se o investimento médio em gastos sociais entre os anos de 2000 e 2016, os investimentos são em educação e cultura $(34,32 \%)$ e saúde e saneamento $(26,24 \%)$. Os demais gastos sociais têm notabilidade baixa, sendo o menor investimento na área de segurança pública. Esse perfil se assemelha com as cidades-polo de Minas Gerais até 105 mil habitantes (Santos \& Andrade, 
2014) e os municípios da região sul do país com o número de habitantes entre 10.001 e 50.000 (Rocha, Lima, \& Piacenti, 2011).

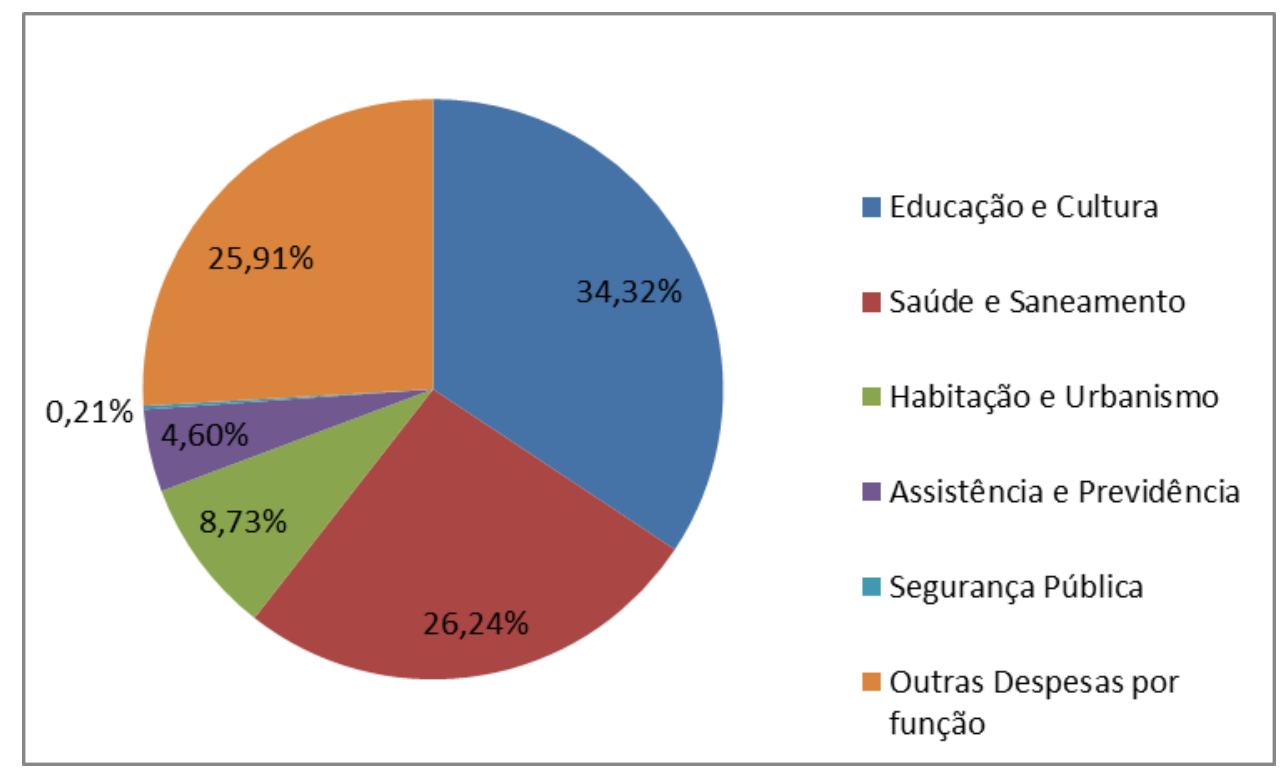

Gráfico 10: Investimento Médio em Gastos Sociais (2000 a 2016).

Fonte: Dados da pesquisa.

O Gráfico 11 mostra a evolução dos gastos sociais no tempo, reforçando as categorias de educação e cultura, e saúde e saneamento como principais. Observou-se um aumento dos investimentos no decorrer dos anos, tendo a educação e cultura o maior valor de investimento, seguida da saúde e saneamento, habitação e urbanismo, assistência e previdência e, por último, da segurança pública. Dentre os anos analisados, vale ressaltar a situação atípica do ano de 2013, quando houve um aumento nas despesas com educação e cultura, o que significou uma redução dos investimentos em todos os outros gastos sociais nesse ano.

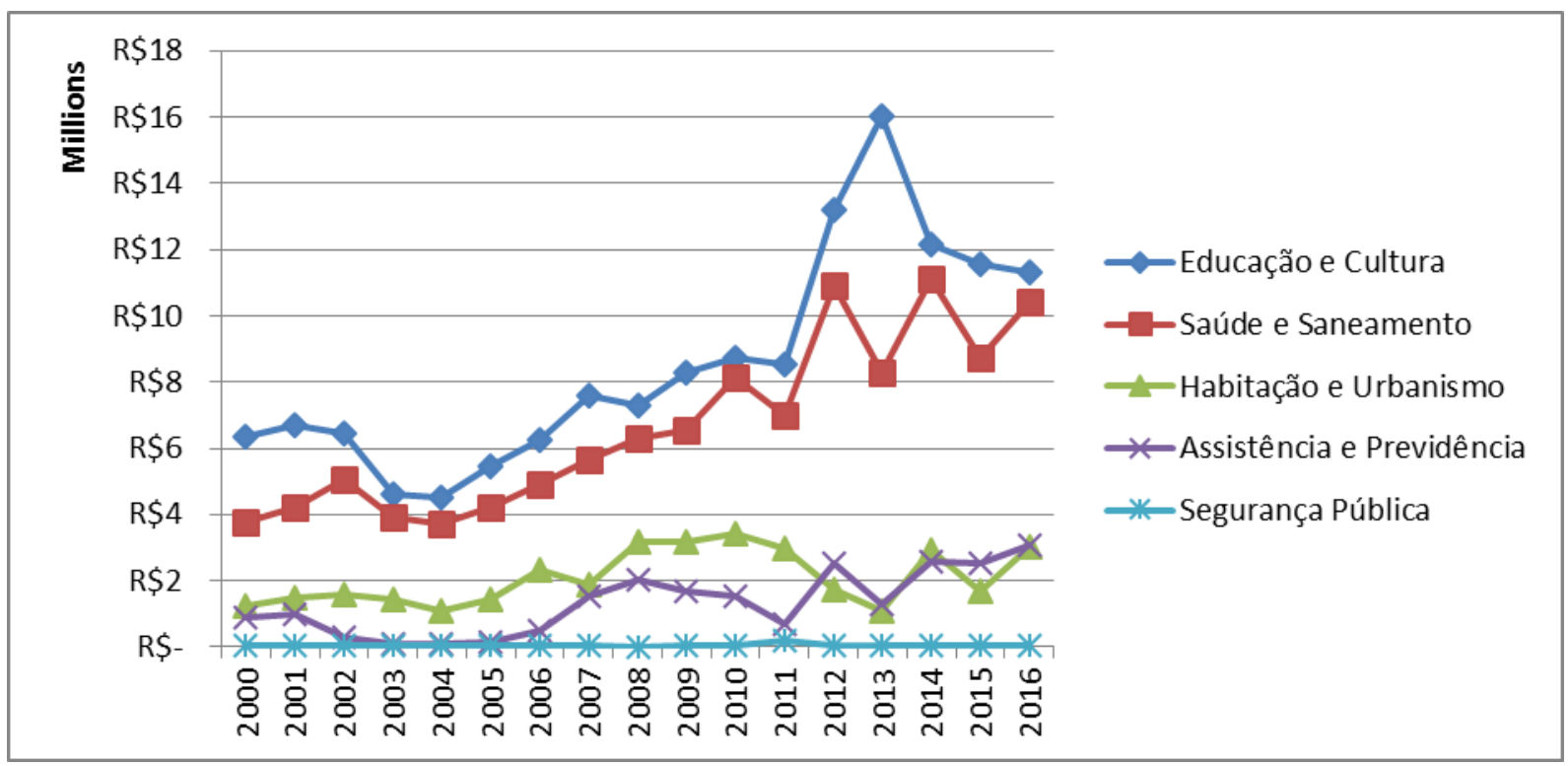

Gráfico 11: Investimento Médio em Gastos Sociais (2000 a 2016). Fonte: Dados da pesquisa. 
Analisando a distribuição orçamentária com base nos limites legais estabelecidos e citados anteriormente, apresenta-se abaixo a Tabela 1 que mostra os limites quanto a despesas com saúde e educação. Nos anos de 2007 a 2013, tanto as despesas com saúde como as despesas com educação respeitaram os limites mínimos constitucionais de $25 \%$ e $15 \%$, respectivamente. Ressalta-se que os dados apresentados foram coletados no TCE/MG e que os dos demais anos que compõem a análise temporal deste estudo não estavam disponíveis.

Tabela 1: Limites constitucionais 2007 a 2013.

\begin{tabular}{lll}
\hline & Despesas com Saúde & Despesas com Educação \\
\hline $\mathbf{2 0 0 7}$ & $18,12 \%$ & $26,69 \%$ \\
\hline $\mathbf{2 0 0 8}$ & $18,85 \%$ & $25,44 \%$ \\
\hline $\mathbf{2 0 0 9}$ & $20,53 \%$ & $26,95 \%$ \\
\hline $\mathbf{2 0 1 0}$ & $22,47 \%$ & $25,86 \%$ \\
\hline $\mathbf{2 0 1 1}$ & $23,29 \%$ & $25,58 \%$ \\
\hline $\mathbf{2 0 1 2}$ & $28,87 \%$ & $25,80 \%$ \\
\hline $\mathbf{2 0 1 3}$ & $24,07 \%$ & $26,47 \%$ \\
\hline
\end{tabular}

Fonte: Fiscalizando com TCE/MG (2017).

Quanto aos limites de gastos com pessoal em relação à receita corrente líquida, verifica-se, na Tabela 2, que, no período apresentado, o município manteve as despesas com pessoal abaixo do limite estabelecido na LRF de $60 \%$, mantendo uma considerável margem de segurança entre os limites praticados e os estabelecidos.

Tabela 2: Limites LRF.

\begin{tabular}{lllllll} 
Tabela 2: Limite LRF. \\
\hline \multirow{2}{*}{ EXERCÍCIO } & \multicolumn{2}{l}{ EXECUTIVO } & \multicolumn{2}{l}{ LEGISLATIVO } & \multicolumn{2}{l}{ MUNICÍPIO } \\
\cline { 2 - 7 } & $\%$ & DESPESA (R\$) & $\%$ & DESPESA (R\$) & $\%$ & DESPESA (R\$) \\
\hline $\mathbf{2 0 0 7}$ & $50,21 \%$ & $\mathrm{R} \$ 5.879 .367,45$ & $2,86 \%$ & $\mathrm{R} \$ 334.576,22$ & $53,07 \%$ & $\mathrm{R} \$ 6.213 .943,67$ \\
\hline $\mathbf{2 0 0 8}$ & $47,76 \%$ & $\mathrm{R} \$ 6.766 .038,14$ & $2,36 \%$ & $\mathrm{R} \$ 333.949,06$ & $50,12 \%$ & $\mathrm{R} \$ 7.099 .987,20$ \\
\hline $\mathbf{2 0 0 9}$ & $50,41 \%$ & $\mathrm{R} \$ 7.704 .899,04$ & $2,61 \%$ & $\mathrm{R} \$ 398.547,28$ & $53,02 \%$ & $\mathrm{R} \$ 8.103 .446,32$ \\
\hline $\mathbf{2 0 1 0}$ & $50,85 \%$ & $\mathrm{R} \$ 8.673 .812,45$ & $2,34 \%$ & $\mathrm{R} \$ 398.494,91$ & $53,19 \%$ & $\mathrm{R} \$ 9.072 .307,36$ \\
\hline $\mathbf{2 0 1 1}$ & $42,44 \%$ & $\mathrm{R} \$ 8.850 .161,23$ & $2,08 \%$ & $\mathrm{R} \$ 434.759,88$ & $44,52 \%$ & $\mathrm{R} \$ 9.284 .921,11$ \\
\hline $\mathbf{2 0 1 2}$ & $49,09 \%$ & $\mathrm{R} \$ 11.724 .570,73$ & $1,81 \%$ & $\mathrm{R} \$ 431.753,19$ & $50,90 \%$ & $\mathrm{R} \$ 12.156 .323,92$ \\
\hline $\mathbf{2 0 1 3}$ & $51,51 \%$ & $\mathrm{R} \$ 12.509 .235,32$ & $3,08 \%$ & $\mathrm{R} \$ 747.825,40$ & $54,59 \%$ & $\mathrm{R} \$ 13.257 .060,72$ \\
\hline
\end{tabular}

Fonte: Fiscalizando com TCE/MG (2017).

Diante do que foi apresentado e tomando por base o que se propõe neste trabalho, constata-se que o município de Ladainha expressa a realidade de municípios que apresentam grande dependência financeira em relação aos entes federados superiores, por uma arrecadação própria insuficiente para atender às demandas da população (Pereira, 2002; Brito \& Dias, 2012; Santos \& Santos; 2012; Ferreira et al, 2016; Leroy \& Bontempo, 2017). Por ser pequeno município, possui atividade econômica pouco expressiva, basicamente rural e têm a prefeitura como o maior empregador (SANTOS \& SANTOS, 2014). Com gastos concentrados principalmente nos denominados Gastos Sociais, havendo um predomínio em Educação e Cultura e na Saúde e Saneamento (Rocha, Lima, \& Piacenti, 2011; Santos \& Andrade, 2014), áreas em que os legisladores definem limites de gastos para desestimular o 
uso dos recursos públicos em outras finalidades, por meio da Constituição de 1988. Positivamente, nota-se que, no período analisado, o município respeitou os percentuais de aplicação de recursos na saúde e na educação, estabelecidos na constituição e também os limites prudenciais de despesas com pessoal estabelecidos na LRF.

\section{Considerações Finais}

Neste trabalho, foi apresentada a proposta de identificar qual o perfil orçamentário do município de Ladainha/MG, no período de 2000 a 2016. Para isso, analisaram-se os dados do período identificando o comportamento temporal das receitas e despesas, ressaltando as com maior representatividade nas classificações de captação e origem de receitas e natureza e finalidade das despesas.

Verificou-se que o município apresentou crescimento das receitas orçamentárias no período e que este foi influenciado principalmente pelo crescimento das receitas correntes. Analisando quanto à captação de recursos, nota-se que as receitas tributárias, em média 2,03\% do total das receitas, têm uma arrecadação insuficiente para suprir as necessidades da população, ocasionando uma dependência das transferências intergovernamentais que representam em média $88,81 \%$ das receitas totais do município no período.

Complementando a análise das receitas, verificou-se que os principais tributos são o IRRF e o ISSQN. Já o IPTU tem uma baixa arrecadação, podendo ser justificado pelo fato do município ser predominantemente rural. Quanto às transferências intergovernamentais, a principal fonte é a União, destacando o FPM, seguido do ICMS (transferência do estado).

$\mathrm{Na}$ análise das despesas orçamentárias, notou-se também o crescimento no período representado pelas despesas correntes. Entre os principais gastos sociais, estão a Educação e Cultura, em média 34,32\% dos investimentos, seguido da Saúde e Saneamento, em média 26,24\%, principais gastos entre os municípios de pequeno porte (Rocha, Lima \& Piacenti, 2011). No que tange aos limites legais analisados nesse período, o município atendeu aos limites constitucionais e limite prudencial de despesas com pessoal.

Como visto na revisão da literatura, esse perfil é uma consequência da proliferação de municípios, que almejavam a emancipação na busca por maior acesso a recursos que não tinham enquanto distritos de outros municípios. Isso fez com que o Estado de Minas Gerais passasse a ter mais de $80 \%$ de seus municípios com população inferior a 20 mil habitantes, porém esses novos municípios desprovidos de uma estrutura institucional acabaram por ter baixa capacidade de arrecadação própria. Essa realidade vai ao encontro da visão ideal da descentralização de gastos apresentada por Giambiagi e Além (2008), em que os entes subnacionais deveriam aumentar a capacidade de arrecadação própria sendo capazes de financiar os seus gastos e tendo, assim, maior responsabilidade fiscal.

A análise temporal neste estudo limitou-se aos dados dos últimos 17 anos e despesas e receitas orçamentárias executadas, não havendo uma comparação entre o que foi previsto e o que foi executado para uma reflexão sobre a gestão municipal e o processo de execução orçamentária, etapa que apresenta grandes desafios para os gestores. Além disso, aponta-se como limitação do estudo a análise de um caso, o que impossibilita compreensões generalizadas sobre o perfil orçamentário identificado para os demais pequenos municípios. Além no número de habitantes, cabe destacar uma característica peculiar a Ladainha que é a sua baixa industrialização e a concentração de seus habitantes no meio rural.

Para maior entendimento dos determinantes dos indicadores analisados, sugere-se que, em futuras pesquisas, seja realizada uma comparação entre as receitas e despesas previstas, além 
de uma maior aproximação do objeto de estudo por meio de entrevistas e questionários respondidos pelos envolvidos no processo.

\section{REFERÊNCIAS}

Almeida, A. (2007). Internacionalização de empresas brasileiras: perspectivas e riscos. Rio de Janeiro: Elsevier.

Andersson, U. \& Forsgren, M. (2000). In Search of Centre of Excellence: network embeddedness and subsidiary roles in multinational corporations. Management International Review, 40, p. 329-350.

Banco Central do Brasil. (2016). Capitais brasileiros no exterior (CBE): ano-base 2015. Brasília, DF.

Banco Mundial. Gross Domestic Product (current US\$). Recuperado em 11 Novembro, 2016, de http://data.worldbank.org/indicator/NY.GDP.MKTP.CD

Barcellos, E. P.; Cyrino, A. B. (2007). Quão internacionalizadas são as nossas multinacionais? Proposta de metodologia e resultados da sua aplicação a empresas brasileiras com atuação no exterior. Anais do Encontro da Associação Nacional de Pósgraduação e Pesquisa em Administração, Rio de Janeiro, RJ, Brasil, 31.

Barney, J. (1991). Firm resources and sustained competitive advantage. Journal of Management 17(1), 99-120.

Bêrni, D. A., \& Fernandez, B. P. M. (2012). Métodos e técnicas de pesquisa: modelando as ciências empresariais. São Paulo: Saraiva.

Blaxter, L., Hughes C., \& Tight, M. (2010). How to research. Berkshire: Open University Press.

Borini, F. M., Ribeiro, F. C. F., Coelho, F. P., \& Proença, E. R. (2006). O prisma da internacionalização: um estudo de caso. FACES, 5(3), p. 42-55.

Cavusgil, S. T., \& Kirpalani, V. (1993). Introducing products into export markets: success factors. Journal of Business Research, 27, p. 1-15.

Cavusgil, S. T., Knight, G., \& Riesenberger, J. R. (2010). Negócios internacionais: estratégia, gestão e novas realidades. São Paulo: Pearson.

Cetra, G. O., \& Oliveira, M. A. S. (2014). Infraestrutura e crescimento regional no Brasil: uma análise da alocação de recursos do Programa de Aceleração do Crescimento (PAC). Revista de Economia e Administração, 13(1), p. 5-29.

Confederação Nacional da Indústria. (2012). Internacionalização das empresas brasileiras: motivações, barreiras e demandas de políticas públicas. Brasília, DF.

Datta, D. K., Herrmann, P., \& Rasheed, A. A. (2002). Choice of foreign market entry modes: critical review and future directions. Advances in International Management. 14, p. 85153.

Dow, D. (2000). A note on psychological distance and export market selection. Journal of International Marketing, 8(1), p. 51-64.

Feldmann, P. R. (2010). Empresas latino-americanas: oportunidades e ameaças no mundo globalizado. São Paulo: Atlas. 
Fleury, A. (2010). Gestão empresarial para a internacionalização das empresas brasileiras. São Paulo: Atlas.

Ferreira, P. C. (1994). Infraestrutura pública, produtividade e crescimento. Pesquisa e Planejamento Econômico,24(2), p. 187-202.

Fleury, A., \& Fleury, M. T. L. (2007). Internacionalização e os países emergentes. Universidade de São Paulo, São Paulo, SP, Brasil.

Floriani, D. E. (2010). O grau de internacionalização, as competências e o desempenho da PME brasileira. Universidade de São Paulo: São Paulo, 307p.

Folster, A., Silveira, T. P., Ferreira, L. F., \& Lunkes, R. J. (2016). Pesquisa empírica em contabilidade tributária: um panorama das pesquisas tributárias no Brasil. REUNIR: Revista de Administração, Contabilidade e Sustentabilidade, 6(1), p. 1-16.

Forsgren, M. (1989). Managing the internationalization process. Londres: Routledge.

Forte, S. H. A. C.; Sette Jr, E. L. M. (2005). Grau de internacionalização de empresas: um estudo no setor de rochas ornamentais e de revestimento no Estado do Ceará. Anais do Encontro da Associação Nacional de Pós-graduação e Pesquisa em Administração, Brasília, DF, Brasil, 29.

Forte, S. H. A. C.; Moreira, M. Z. (2007). Internacionalização das maiores empresas exportadoras do setor calçadista brasileiro: estudo do perfil, estratégias e desempenho. Anais do Encontro da Associação Nacional de Pós-graduação e Pesquisa em Administração, Rio de Janeiro, RJ, Brasil, 31.

Global Entrepreneurship Monitor. (2014). Empreendedorismo no Brasil. Curitiba: IBQP.

Hair Jr, J. F., Black, W. C., Babin, B. J., Anderson, R. E., \& Tatham, R. L. (2009). Análise multivariada de dados. Porto Alegre: Bookman.

Hitt, M. A., Hoskissom, R. E. \& Kim, H. (1997). International diversification: effects on innovation and firm performance in product-diversified firms. Academy of Management Journal, 40(4), p.767-798.

Honorio, L. C. (2009). Grau de internacionalização de empresas brasileiras de manufaturados e a influência de fatores organizacionais e estratégicos. Revista de Administração Mackenzie, 10(5), p. 154-180.

Hoskisson, R. E., Wright, M., Filatotchev, I., \& Peng, M. W. (2013). Emerging multinationals from mid-range economies: the influence of institutions and factor markets. Journal of Management Studies, 50(7), p. 1295-1321.

International Finance Corporation. (2011). Enterprise surveys: Brazil - 2009. Washington: GIAEA.

Johanson, J., \& Vahlne, J. E. (1977). The internationalization process of the firm - a model of knowledge development and increasing foreign market commitments. Journal of International Business Studies, p. 23-32.

Johanson, J., \& Vahlne, J. E. (1990). The mechanism of internationalization. International Marketing Review, 7(4), p.11-24.

Khoury, T. A., \& Peng, M. W. (2011). Does institutional reform of intellectual property rights lead to more inbound FDI? Evidence from Latin America and the Caribbean. Journal of World Business, 46, p. 337-345. 
Martins, G. A., \& Pelissaro, J. (2005). Sobre conceitos, definições e constructos nas ciências contábeis. BASE - Revista de Administração e Contabilidade da Unisinos, 2(2), p. 7884.

Martins, G. A., \& Theóphilo, C. R. (2009). Metodologia da investigação científica para ciências sociais aplicadas. São Paulo: Atlas.

Mendes, Z., \& Ferreira, G. T. C. (2013). Negócios internacionais e suas aplicações no Brasil. São Paulo: Almedina Brasil.

Oliveira, M. A. S., \& Teixeira, E. C. (2006). Desoneração tributária dos serviços de infraestrutura no Brasil: uma análise do equilíbrio geral. Reuna, 11(2), p. 35-58.

Oliveira Jr, M, M. (2010). Multinacionais brasileiras: internacionalização, inovação e estratégia global. Porto Alegre: Bookman.

Passos, G. D., \& Mendes da Silva, W. (2014). Legislação específica para infraestrutura e P\&D induz redução de risco de debêntures no Brasil. Revista de Finanças Aplicadas, 2, p. 1-35.

Peng, M. W. Estratégia global. (2008). São Paulo: Thomson Learning.

Peng, M., Sun, S., Pinkham, B., Chen, H., (2009). The institution-based view as a third leg for a strategy tripod. The Academy of Management Perspectives 23(3), p. 63-81.

Peng, M. W., \& Parente, R. C. (2012). Institution-based weaknesses behind emerging multinationals. Revista de Administração de Empresas, 52(3), p. 360-364.

Penrose, E. (1959). The theory of the growth of the firm. Oxford: Oxford University Press.

Pohlmann, M. C., \& Iudícibus, S. (2006). Classificação da pesquisa tributária: uma abordagem interdisciplinar. Enfoque: Reflexão Contábil, 25(3), p. 57-71.

Porter, M. E. (1980). Competitive Strategy. The Free Press, New York.

Gilpin, R. (2001). Global Political Economy. Princeton: Princeton University Press.

Reuber, A. R., \& Fischer, E. (1997). The influence of the management team's international experience on the internationalization behaviors of small and medium-sized enterprises. Journal of International Business Studies, 28(4).

Root, F. R. (1994). Entry strategies for international markets. New York: Lexington Books.

Sampieri, R. H., Collado, C. F., \& Lucio, P. B. (2006). Metodologia de pesquisa. São Paulo: McGraw-Hill.

Sullivan, D. (1994). Measuring the degree of internationalisation of a firm. Journal of International Business Studies, 34(2), p. 165-186.

Stöttinger, B., \& Schlegelmich, B.B. (1998). Explaining export development through psychic distance: enlightening or elusive? International Marketing Review, 15(5), p. 357-372.

Tallman, S., \& Li, J. (1996). Effects of international diversity and product diversity on the performance of multinational firms. Academy of Management Review, v. 39(1), p. 179196.

Tanure, B., \& Duarte, R. G. (2006). Gestão internacional. São Paulo: Saraiva.

Turolla, F. A. (2013). Towards a theory of international production of infrastructure services. Revista Eletrônica de Negócios Internacionais, 8(1), p. 17-30. 
United Nations Conference on Trade and Development. (2016) World investment report 2016: investor nationality: policy challenges. Geneva: United Nations.

United Nations Educational, Scientific and Cultural Organization (2001). MOST Annual Report. Recuperado de http://www.unesco.org/most/most_ar_part1c.pdf.

Welch, L. S., \& Luostarinem, R. (1988). Internationalisation: evolution of a concept. Journal of General Management, 14(2), p. 34-55.

Zahra, S. A., Ireland, D. R., \& Hitt, M. A. (2000). International expansion by new venture firms: international diversity, mode of market entry, technological learning and performance. Academy of Management Journal, 43(5), p. 925-950.

Zhu, Y., Wittmann, X., \& Peng, M. W. (2011). Institution-based barriers to innovation in SMEs in China. Asia Pacific Journal of Management, 29, p. 1131-1142.

\footnotetext{
i Adotou-se como comparativo o ano de 2015 para uma análise real de crescimento, visto que os valores apresentados em 2016 são referentes a receitas previstas na LOA.

ii Utilizou-se esse período de comparação pois houve alteração na apresentação do Plano de Contas do Município, o que realocou algumas receitas alterado os valores somados.
} 